\title{
Efficient wood and fiber characterization - A key factor in research and operation
}

\author{
Sven-Olof Lundqvist* \\ STFI, Swedish Pulp and Paper Research Institute, Box 5064, 11486, Stockholm, Sweden
}

(Received 28 September 2001; accepted 12 April 2002)

\begin{abstract}
During recent years, there have been a tremendous development in biotechnology. When entering the phase of industrial application, new possibilities have to be combined with a knowledge of the demands of the "users" concerning product quality, production efficiency, etc. It is also crucial to understand the natural variability of the wild-type plants and age-to-age relationships. Efficient measurement methods are key factors for progress in this field, in both research and operation. At STFI, the Swedish Pulp and Paper Research Institute, new tools and knowledge for improved wood and fiber utilization have been developed. Methods for the characterization of wood and fiber properties are emphasized. In this paper, measurement methods and variability in wood and fiber properties are illustrated. The methods used at STFI are useful not only for research on pulp and paper but may contribute also to projects in wood technology, forestry, tree improvement and biotechnology.
\end{abstract}

wood / fiber, property / characterization / application

Résumé - La caractérisation rapide des propriétés du bois et des fibres. Une clé pour la recherche et les industries forestières. Ces dernières années ont connu un développement remarquable en matière de biotechnologie. Pour passer aux applications industrielles, ces nouvelles possibilités doivent être confrontées aux demandes des utilisateurs concernant la qualité des produits ou la productivité des procédés. Il est crucial aussi de bien maîtriser la variabilité des individus en peuplements naturels et les relations juvéniles/adultes au sein d'un même arbre. Pour répondre à ces objectifs, aussi bien au stade de la recherche que de la production, il est nécessaire de disposer de méthodes de mesures rapides. De nouveaux outils et savoirs pour une meilleure utilisation du bois et des fibres ont été développés à l'Institut suédois de recherche sur la pâte et le papier (STFI). Ces méthodes d'investigation et la variabilité des propriétés du bois et des fibres ainsi mesurées sont illustrées dans ce travail. Elles s'avèrent utiles non seulement pour la pâte et le papier mais peuvent aussi contribuer à des projets en matière de technologie du bois, de foresterie, d'amélioration des arbres et de biotechnologie.

bois / fibre, propriétés / caractérisation / application

\section{INTRODUCTION}

During recent years, tremendous developments have taken place in biotechnology. In the field of tree improvement, new methods have increased the knowledge base, links to wood properties have been investigated and genetic applications are now being approached. When entering the phase of application, many very practical questions have to be answered about these new materials: Are these trees better? How do we judge that? How long do we have to wait to know?

For such judgments, the new possibilities in biotechnology have to be combined with a knowledge of the natural variability of wild-type trees and with the demands of the "users" - forest owners, mills, converters and consumers regarding properties, production efficiency, costs, environmental effects, etc. Otherwise, there is a major risk that the genetic applications will not be successful.

In this paper, examples are given of the need for investigations of natural variability and customer demands. Efficient methods for wood and fiber characterization are crucial for such investigations. The potential of some useful measurement techniques is illustrated.

STFI, the Swedish Pulp and Paper Research Institute, has for many years been engaged in research towards better wood

* Correspondence and reprints

Tel.: +46 8 6767151; fax: +46 84115518 ; e-mail: svenolof.lundqvist@stfi.se 
and fiber utilization. Keywords are measurements, property variability, models and a holistic perspective from tree to product. The examples given in this paper are taken mainly from activities at STFI in two projects within the Fifth Framework Research Programme of the European Commission. The first project, POPWOOD, is coordinated by CNRS/ISV. Its main objective is generation of more productive trees of poplar or aspen. The second project, EuroFiber, is coordinated by STFI. Its objective is a more optimal selection of wood raw materials, focusing on improved paper quality and greater production efficiency for products based on mechanical pulp made from Norway Spruce.

\section{INDUSTRIAL DEMANDS}

Hardwood fibers are often very good as raw material for printing papers. The small fibers contribute to high light scattering and an opaque paper and to smooth surfaces for good printing. Fibers from eucalypts are often used. Poplars constitute a large family of hardwood species growing in large parts of the temperate zone of the Northern hemisphere. A widespread species of this family is Populus tremula, also called aspen. Aspen is also a very good raw material for printing papers and an increase in the production of aspen pulpwood per hectare would be very welcome. Tree improvement efforts should not, however, focus only on volume growth. The properties of the wood fibers and vessel elements of the wood are also crucial.

\subsection{Vessel elements and paper}

For many hardwood species, the vessel elements are a major problem in paper-making. Figure 1a is a microscopy image of pulp from Eucalyptus grandis, showing many slender fibers and one very large vessel element. Figure $1 b$ shows the surface of a printing paper, where such a vessel element has loosened. This will cause a blemish in the print. Loose vessel elements can also adhere to printing plates and lead to a further deterioration in print quality. They can cause dust problems. The vessels serve a purpose in the living tree, but in a papermaking perspective they are not wanted. When hardwood trees are developed to become a raw material for pulp and paper, the vessel elements should be fewer and smaller or easier to separate from the fiber material. And the fiber properties, for instance the fiber dimensions, should be equally or more suitable for the specific product. Uniformity is also important.

\subsection{Automicroscopy of fibers and vessel elements}

The role of STFI in the POPWOOD project is to characterize the properties of fibers and vessel elements, to determine their natural variability and to evaluate their industrial potential. For this purpose, methods are developed to analyze the full variability of the individual fibers and vessel elements in the wood matrix, in order to determine and compare properties of fibers and vessel elements in wild-type poplar with those in new plant materials. The objective is the automatic, or semi-automatic, measurement of different features on large images with microscopic resolution. The sample, up to $10 \mathrm{~cm}$ long, is positioned on a motorized stage. Images are recorded using a light microscope and a digital camera. The images are matched and stitched together into larger images. The image in figure 2, for example, has been built up from 9 sub-images. The fibers and vessel elements are identified and a range of parameters determined.

The analysis shows that the image in figure 2 contains close to 400 small fibers and 9 large vessel elements. In figure 3, all these objects have been sorted according to size and presented according to their semi-perimeter, which corresponds to their widths in the collapsed state in the sheet of paper (if shrinkage etc. in the process is not taken into account), see figure $1 b$. The objects are also related to their cross-sectional areas in the wood. The vessel elements are few, but they account for $37 \%$ of the wood volume of the sample. It is also seen that the semi-perimeters of the vessels are about 4 times broader than those of the fibers. In this sample, $37 \%$ of the wood volume is not useful for paper-making! Tree improvement should definitely not lead to an increase in this proportion.

\section{NATURAL VARIABILITY}

The natural variability has to be established as a basis for judging whether or not new trees are better than existing wild-type trees. Figure $4 a$ shows the radial variation in wood density of 29 trees of Eucalyptus nitens [2]. There are large differences in both density and its radial variation. New plant materials should be compared with such data from existing materials, for density and its uniformity and for all other important properties.

From such data, a conclusion can also be drawn concerning the age at which a judgement of the wood's "usefulness" should be made. The more the graphs cross each other, the longer is it necessary to wait. Figure $4 b$ is calculated from the data in figure $4 a$ and shows how many trees would be wrongly judged if the judgment were made based on the current density at different ages. If trees were selected for their high density at two years of age, $43 \%$ of the selected trees would not be future high-density trees. After 10 years, the rate of failure is down to $7 \%$. Similar investigations are now being performed within the POPWOOD project. This is illustrated in figure 5, which shows the fiber length variability in a set of 7 logs. This set is too limited for any conclusions to be drawn, but more material is being collected and characterized. 


\section{AVAILABLE MEASUREMENT TECHNIQUES}

The natural variability of wood and fiber properties and its consequences are also being investigated in the EuroFiber project, focusing on Norway spruce. The project encompasses the whole production chain from the tree to the product. Project partners are STFI, SkogForsk, AFOCEL, CSIRO, several other research groups, one process equipment supplier and five paper mills. The project includes characterization and modeling, as well as experiments in the laboratory, in a pilot plant and in mills. Many properties of wood and fibers are being measured at several levels of detail.

The arsenal of measurement techniques available today for research and development, and used in the EuroFiber project, is here illustrated by maps showing within-tree variations for various wood and fiber properties. All the maps show variations within the same tree, a Norway spruce from a stand with a high site index on latitude $59^{\circ} \mathrm{N}$, the same as Stockholm. The tree was 71 years old, $33 \mathrm{~m}$ high and $36 \mathrm{~cm}$ wide at breast height, a dominant tree within the stand.

\subsection{Growth pattern}

Figure 6 illustrates how the growth processes of the tree are reflected in the structure of softwood (Picea abies). Each growth ring is composed of earlywood with thin-walled fibers and latewood with thick-walled fibers. The first rings at each height in the tree, figure $6 a$, contain juvenile wood with short fibers. These rings are often broad with a low proportion of latewood. Further out, mature wood is formed with longer fibers, often with more narrow rings with a higher proportion of latewood, figure $6 b$. The ring pattern therefore reflects not only the growth of the tree but also its fiber properties.

In the STFI Wood Measurement Laboratory, wood samples are prepared. The samples are scanned and the growth ring patterns are characterized by image analysis [5]. The widths of all growth rings and all latewood bands are determined in different directions, as in figure 7, to the north and to the south, as well as juvenile and mature wood. Juvenile wood, young mature wood and mature wood are in this case defined as being delimited by the growth rings 15 and 30 .

From such measurements at different heights in the trunk, indicated in gray, the "growth increment mesh" within the tree may be constructed, as shown in figure 8a. The mesh defines the annual increments in the radial and longitudinal directions of each year during the life of the tree. This increment mesh is a good basis for studies of growth. It is also used as a backbone for different types of calculations and presentations. One example is the full tree property map in figure $8 b$, presenting the variation in latewood content within the tree.

\subsection{Wood density and moisture}

A new procedure for measuring the basic wood density (dry mass divided by the green volume) and moisture distribution has been developed by STFI and researchers in wood technology at Luleå Technical University [4]. Density, moisture and features like heartwood and compression wood may be determined with spatial resolution over full log cross-sections, see figure 9. To the left, a color image of a fresh wood disc is shown. To the right, the fresh sample has been run in a computer tomograph, providing an image representing the green density variation (dry wood plus water) and the shape of the cross-section in the green condition. The bright areas have a higher green density than the dark areas. They indicate sapwood, which has a higher moisture content than the drier heartwood in the middle of the stem. The disc is then dried and run again in the tomograph, providing an image of the density of the dry wood (not shown). The shape of that image is, however, deformed by shrinkage during drying. Software from the cinematographic industry is used to transform the deformed dry wood image back to its original shape, which yields the image of the basic wood density shown in the middle of figure 9. In this image, a section of compression wood may be seen. Through further calculations, the moisture distribution in the full stem cross-section may be obtained. And from measurements at different heights, the basic wood density and the moisture content (water per dry wood) throughout the stem can be studied, as well as the location of heartwood and sapwood, see figure 10.

\subsection{Fiber dimensions}

For information regarding the fiber length and fiber width and their radial variation, sub-samples are produced from groups of growth rings, representing juvenile wood, young mature wood and fully mature wood. The fibers are liberated and analyzed with the STFI FiberMaster instrument, which performs an automatic image analysis of objects in a dilute pulp suspension [3]. Figure 11 shows the length and width of fibers from two such sub-samples from the same disc: juvenile wood (growth rings 1 to 15) and mature wood (ring 31 and outwards). The averages for each sub-sample are shown with larger symbols, illustrating the fact that the fiber length and width both increase outwards. Even more evident is the large variability, which makes it important to determine not only averages but also the statistical distributions for the investigated variables.

Figure 12 shows the variability maps in fiber length and fiber width for the spruce, based on averages for groups of growth rings. The vertical fields indicate the extent of juvenile wood; young mature wood and fully mature wood, delimited by annual growth rings 15 and 30 . The colors show the average fiber length of these wood types at different heights, increasing from $2 \mathrm{~mm}$ close to the pith to $3.5 \mathrm{~mm}$ in 


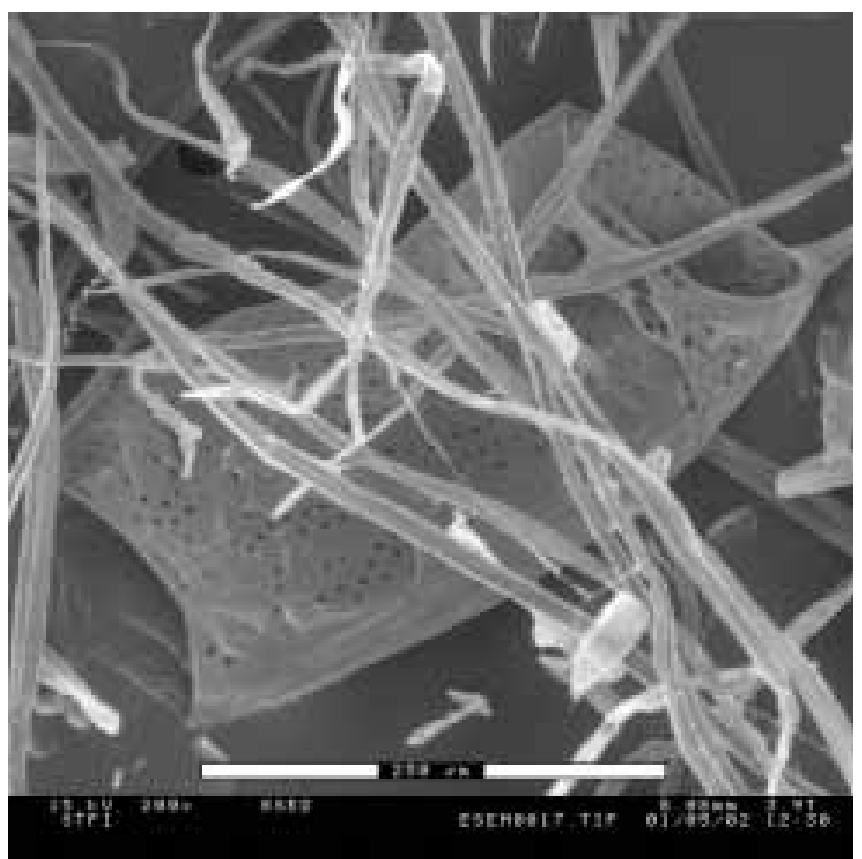

1a. Pulp

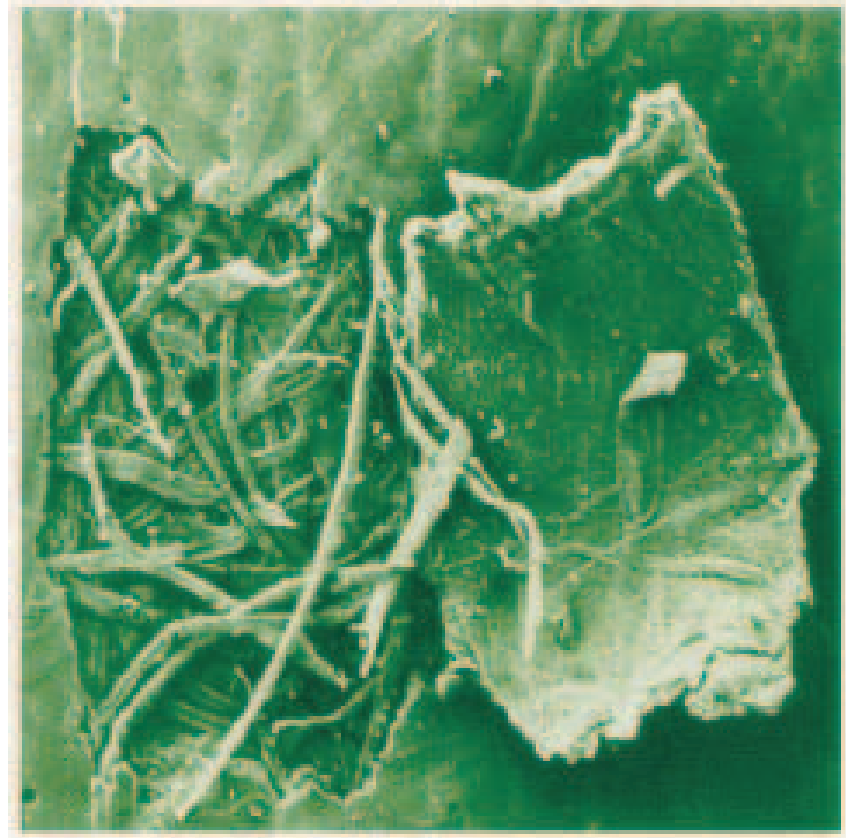

1b. Paper

Figure 1. Fibers and vessel elements from Eucalyptus grandis, to the left in pulp and to the right on a coated paper surface, on similar scales. The surface for printing has been damaged by a loosened vessel element. (Photos: STFI and Griffiths).

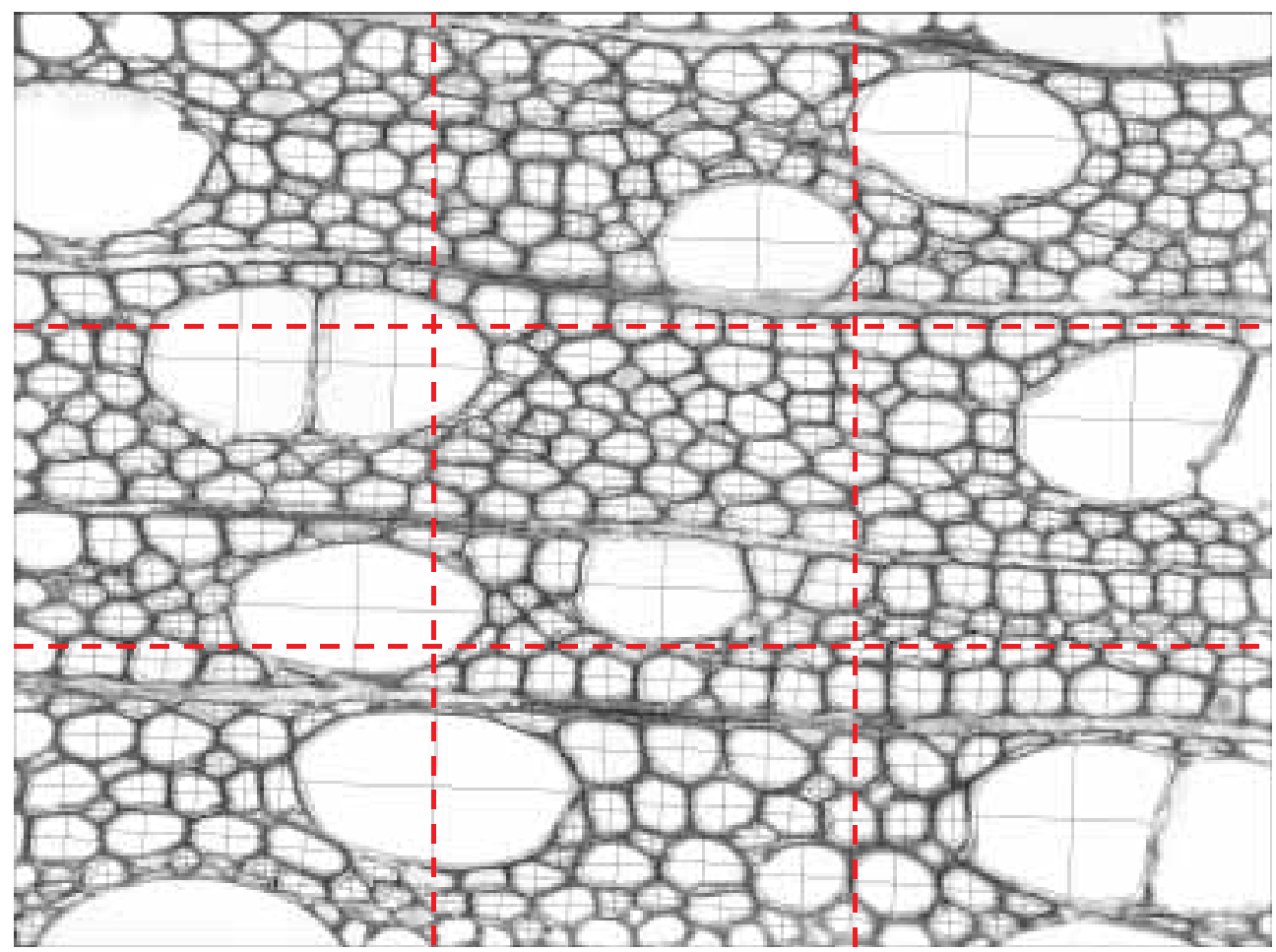

Figure 2. Microscope images automatically matched together and analyzed by a new method under development at STFI. The crosses indicate a fiber or a vessel element that has been analyzed. The average perimeter is about $50 \mu \mathrm{m}$ for the fibers and about $220 \mu \mathrm{m}$ for the vessel elements. 


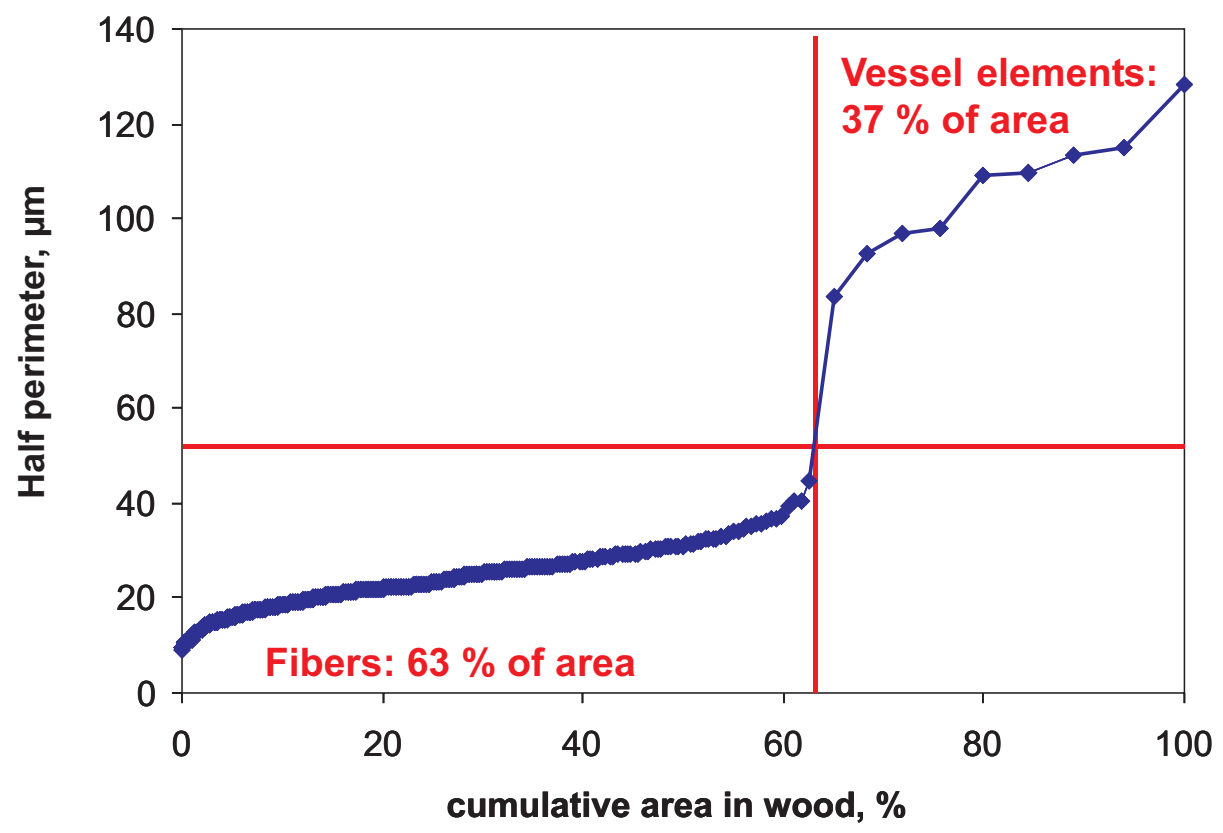

Figure 3. Semi perimeter of fibers and vessel elements in the wood sample of figure 2, measured with a new method under development at STFI. The sample contains about 400 fibers and 9 vessel elements. These vessel elements constitute $37 \%$ of the total area (and volume) of the sample.

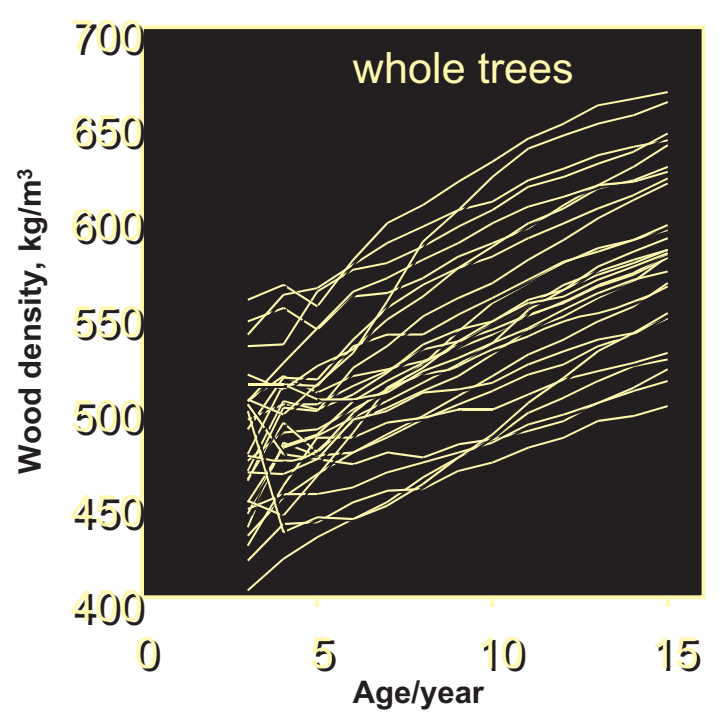

4a. Radial variation

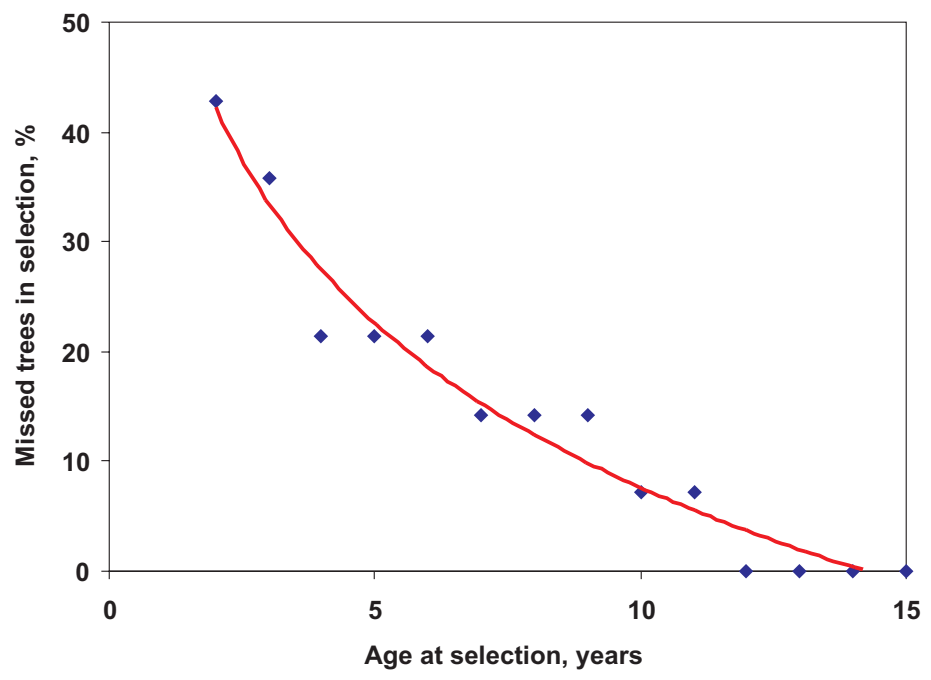

4b. Errors in selection

Figure 4. To the left, the natural radial variability in wood density of the first 15 growth rings in 29 trees of Eucalyptus nitens [2]. To the right, the percentage of wrong decisions, if the 14 trees with the highest future density at different ages were selected on the basis of the current density. 


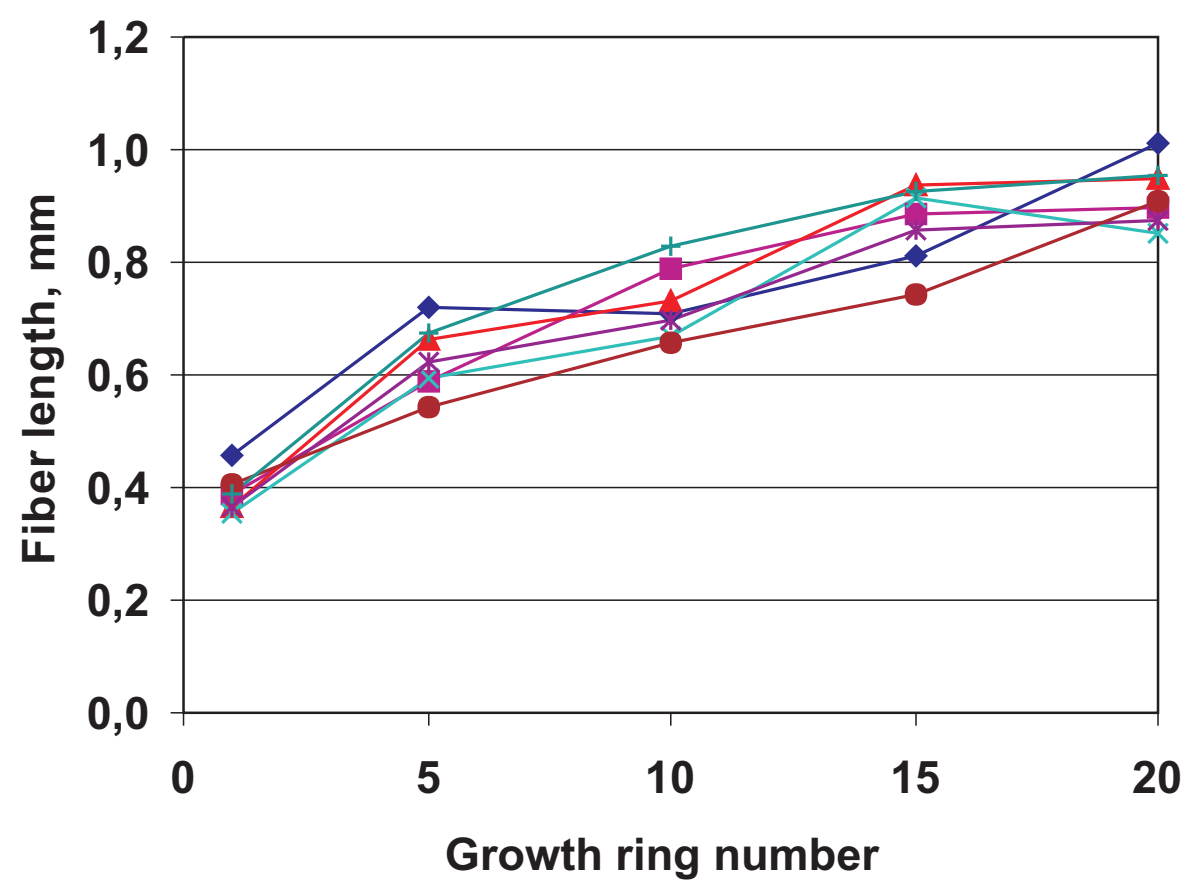

Figure 5. Radial variation in fiber length in a set of $7 \mathrm{logs}$ of Populus tremula (aspen). This set is too small for conclusions to be drawn regarding the predictability of the fiber length in the future, but more material is being analyzed.

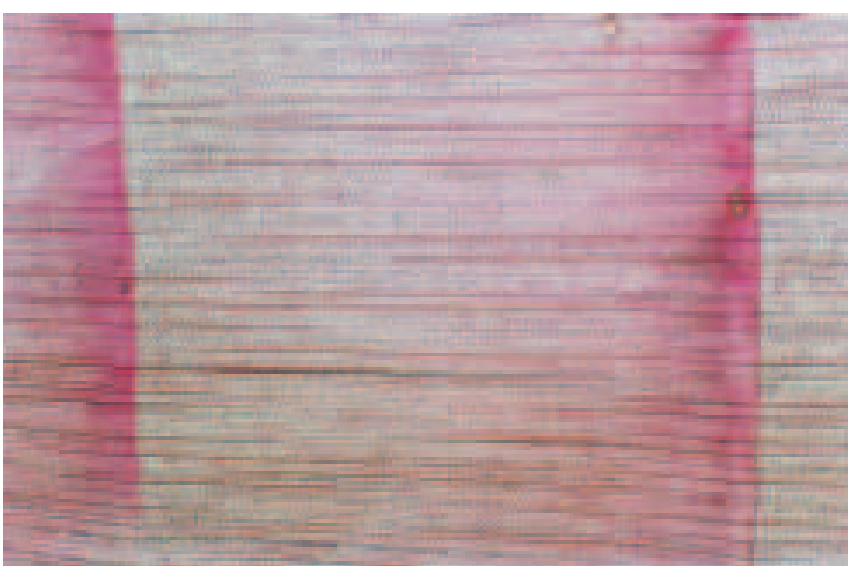

6a. Juvenile wood in pulpwood

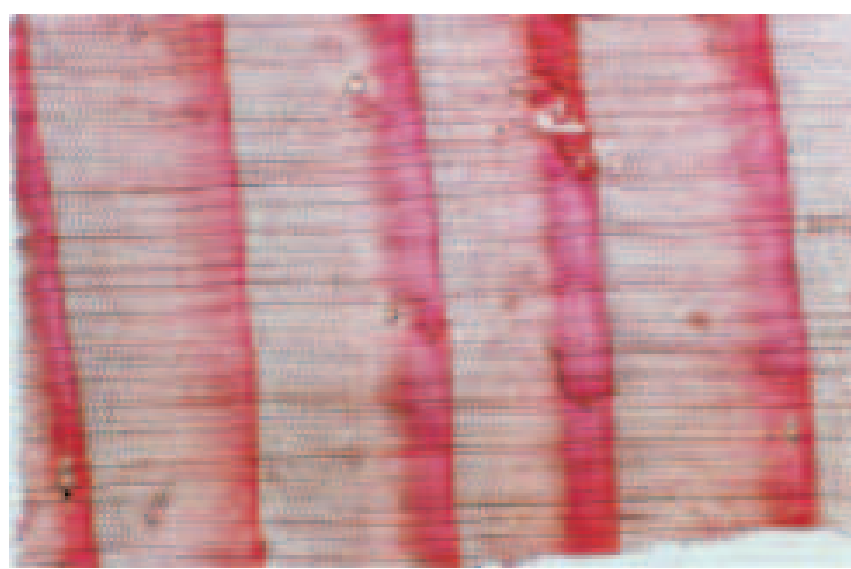

6b. Mature wood in sawmill chips

Figure 6. Fiber cross-sections in two wood samples of the same size from Picea abies. The sample to the left shows juvenile wood from close to the pith, a broad growth ring with a low proportion of latewood. The one to the right shows mature wood further out from the pith, narrower growth rings with a higher proportion of latewood. 

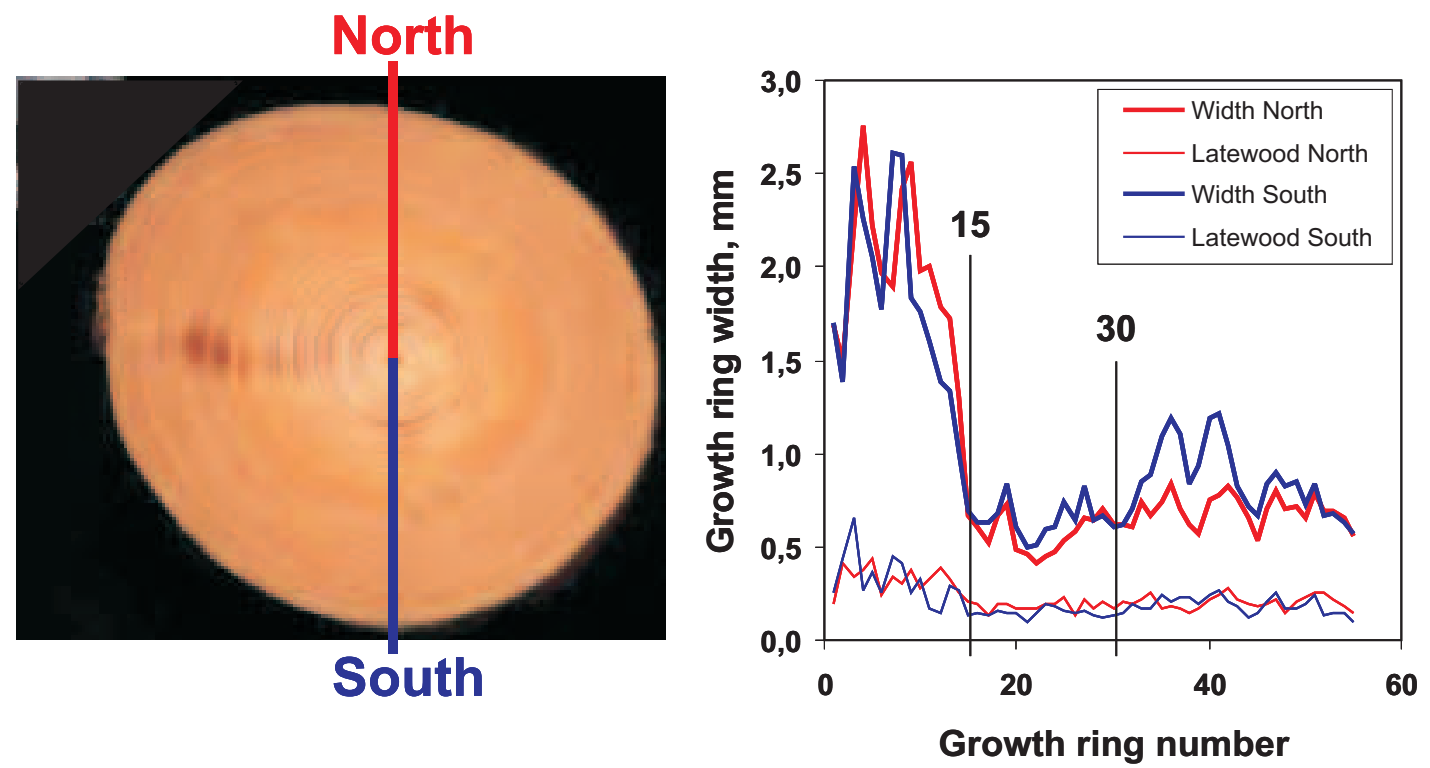

Figure 7. Wood disc and the total widths and latewood band widths of all annual rings in two directions. In this case, limits for juvenile, young mature and mature wood have been set at rings 15 and 30 respectively. The analysis was performed in the STFI Wood Measurement Laboratory. The disc has a diameter of $12 \mathrm{~cm}$.

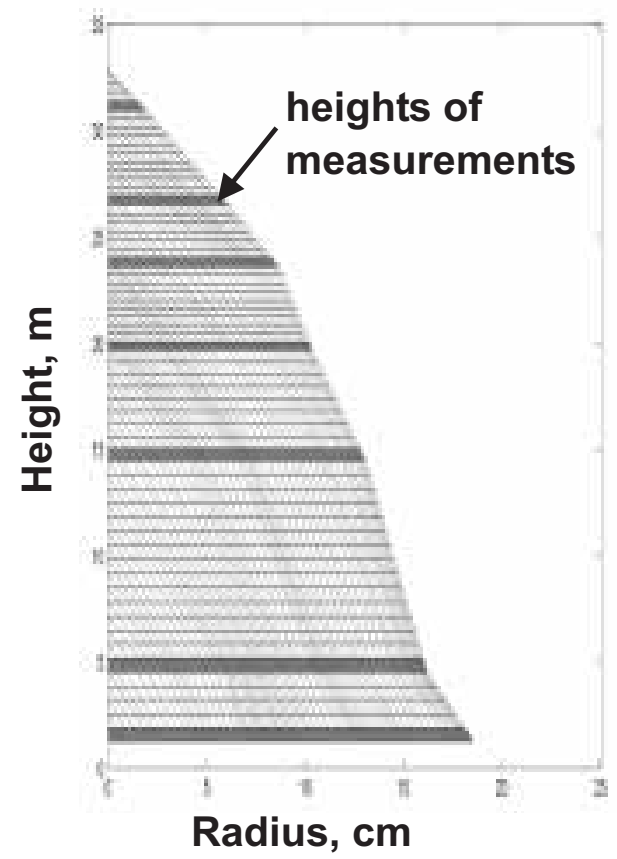

8a. Increment growth mesh

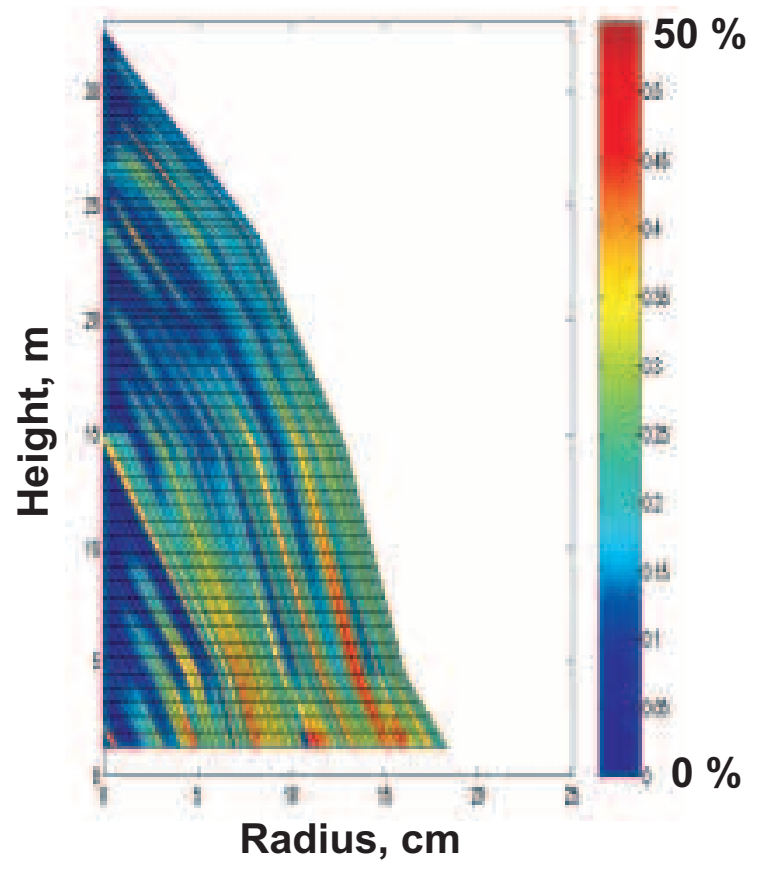

8b. Latewood content

Figure 8. To the left, the growth increments in the stem of a Norway spruce in the radial and longitudinal directions, calculated from measurements at some heights, indicated in gray. The stem is $33 \mathrm{~m}$ high and $36 \mathrm{~cm}$ wide at breast height $(1.3 \mathrm{~m})$. To the right, a property map for the tree, showing the variations in the latewood content within the tree. 


\section{Color image}

\section{Basic density}

Green density

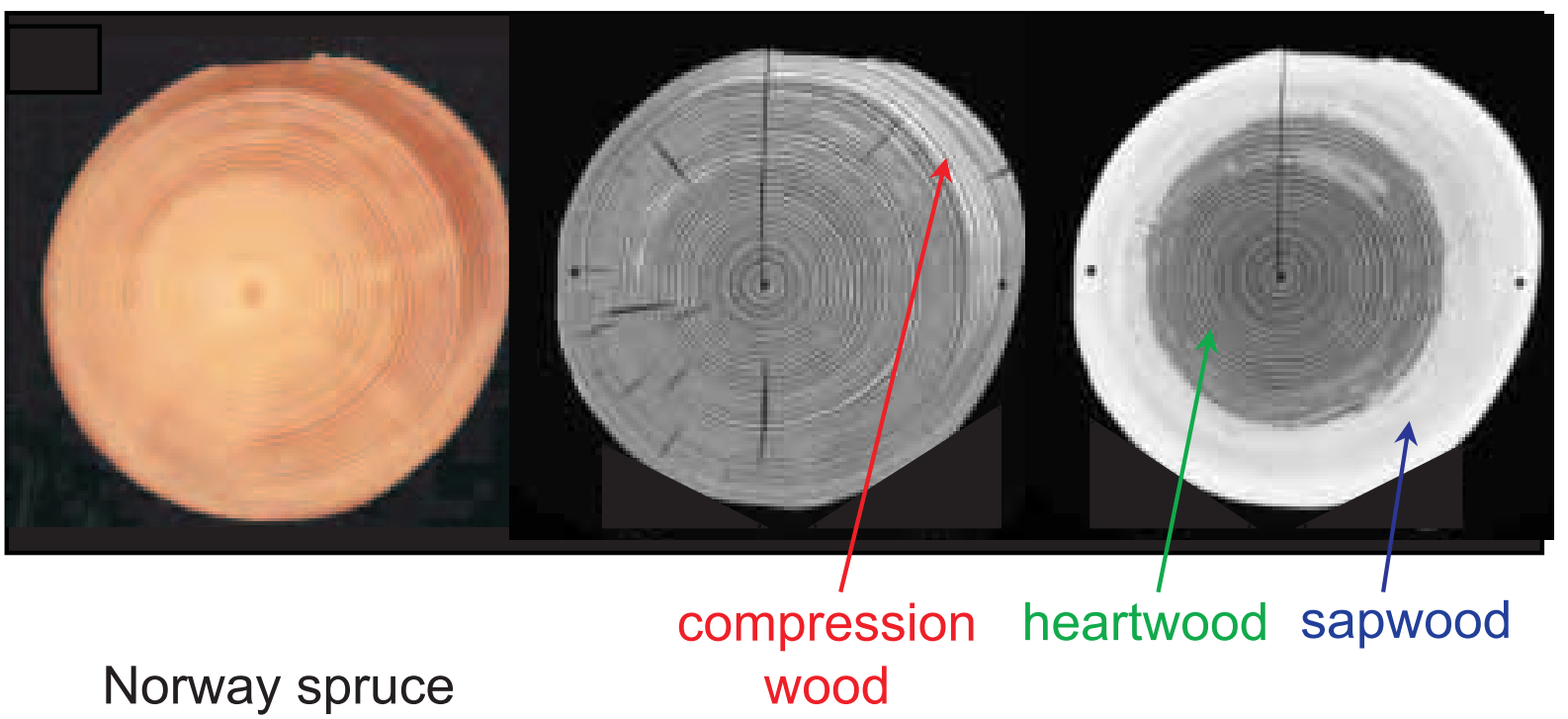

Figure 9. Images of a wood sample. To the left, its appearance in visible light. In the middle the cross-sectional variation in wood basic density. To the right the variation in green density (including moisture). Features like compression wood, heartwood and sapwood may be observed. The measurements were performed with a new procedure based on computer tomography developed by STFI and LTU.

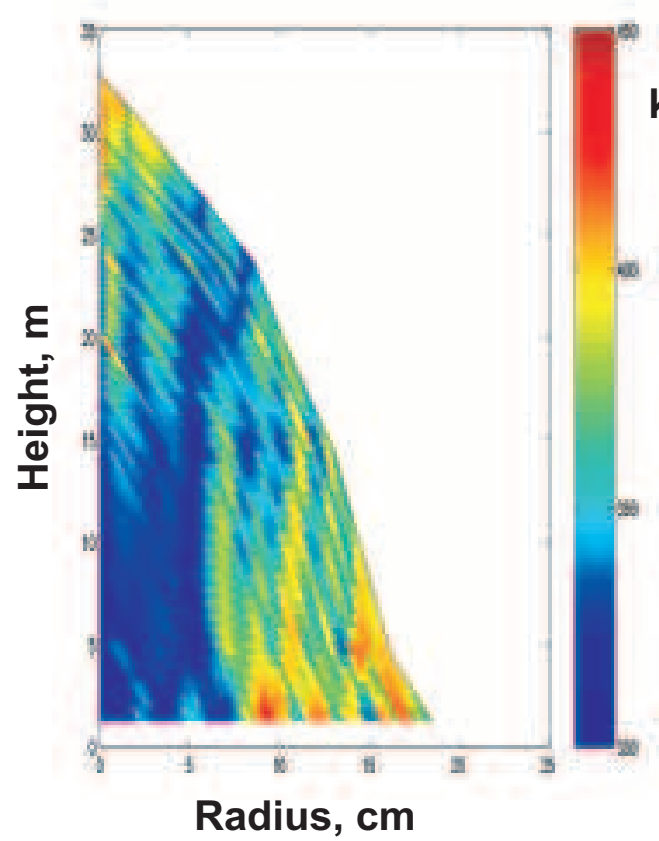

10a. Basic wood density
450

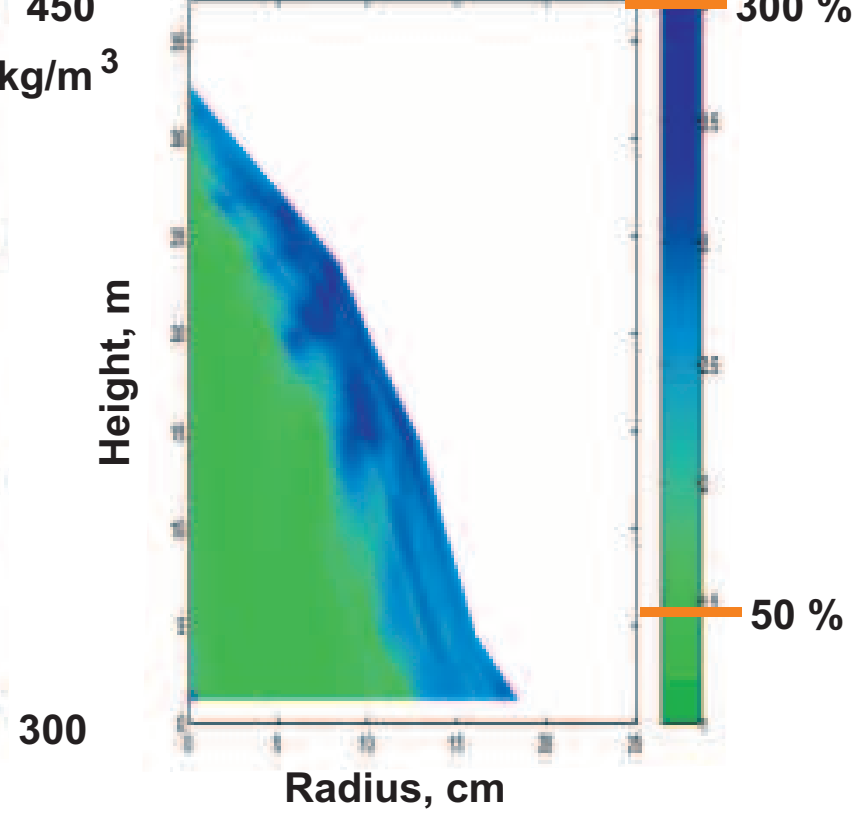

10b. Wood moisture content

Figure 10. Property maps showing the within-tree variations, to the left in basic wood density (dry mass per green volume) and to the right in wood moisture content (water per dry wood), determined by a method based on computer tomography developed by STFI and LTU. Same tree as in figure 8. 


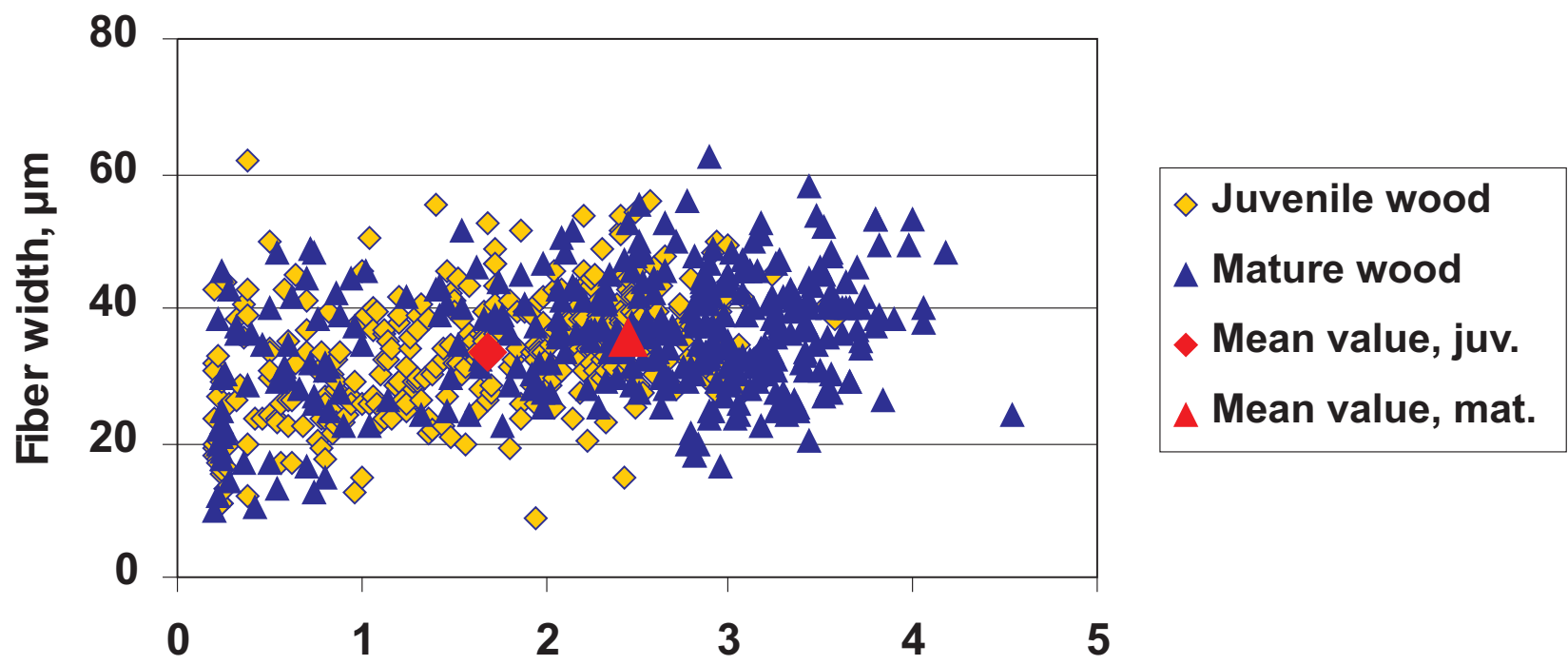

Fiber length, $\mathrm{mm}$

Figure 11. Lengths and widths of fibers from sub-samples representing juvenile wood (growth rings 1-15) and mature wood (growth rings $>30$ ). The averages of each fiber ensemble are also indicated. Measurements performed with a STFI FiberMaster instrument.

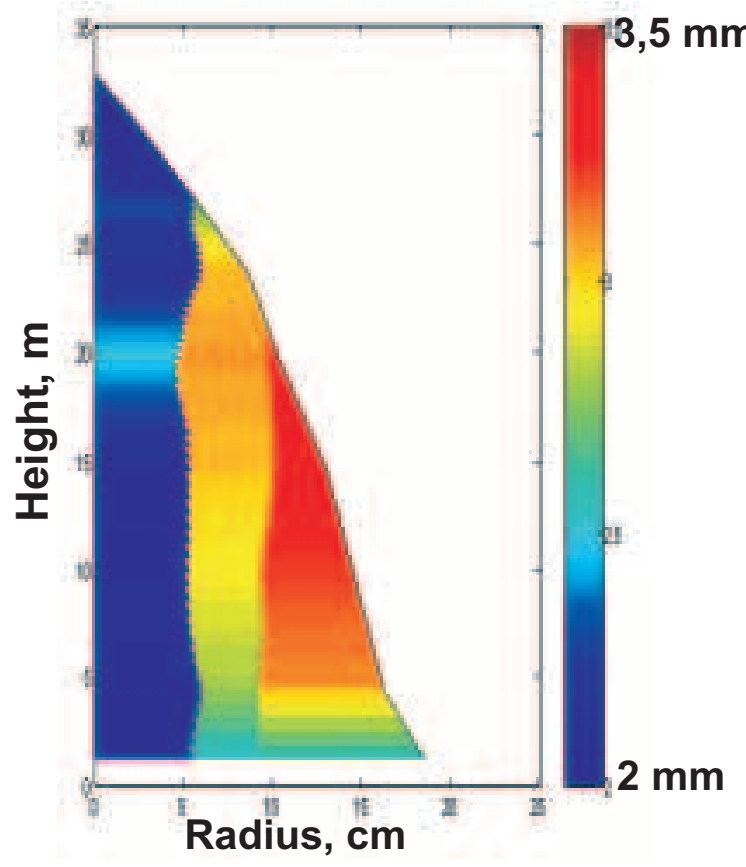

12a. Fiber length

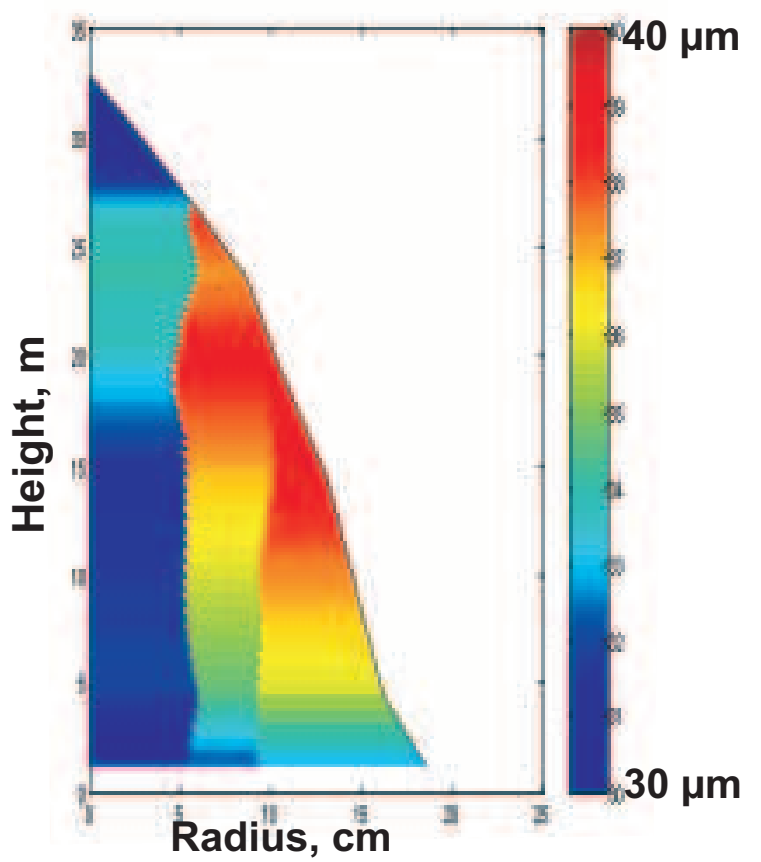

12b. Fiber width

Figure 12. Property maps showing the within-tree variations in fiber length (left) and fiber width (right), based on averages for growth ring widths representing juvenile wood (rings 1-15), young mature wood (16-30) and mature wood (> 30). The fiber dimensions were determined with a STFI FiberMaster instrument. Same tree as in figure 8. 


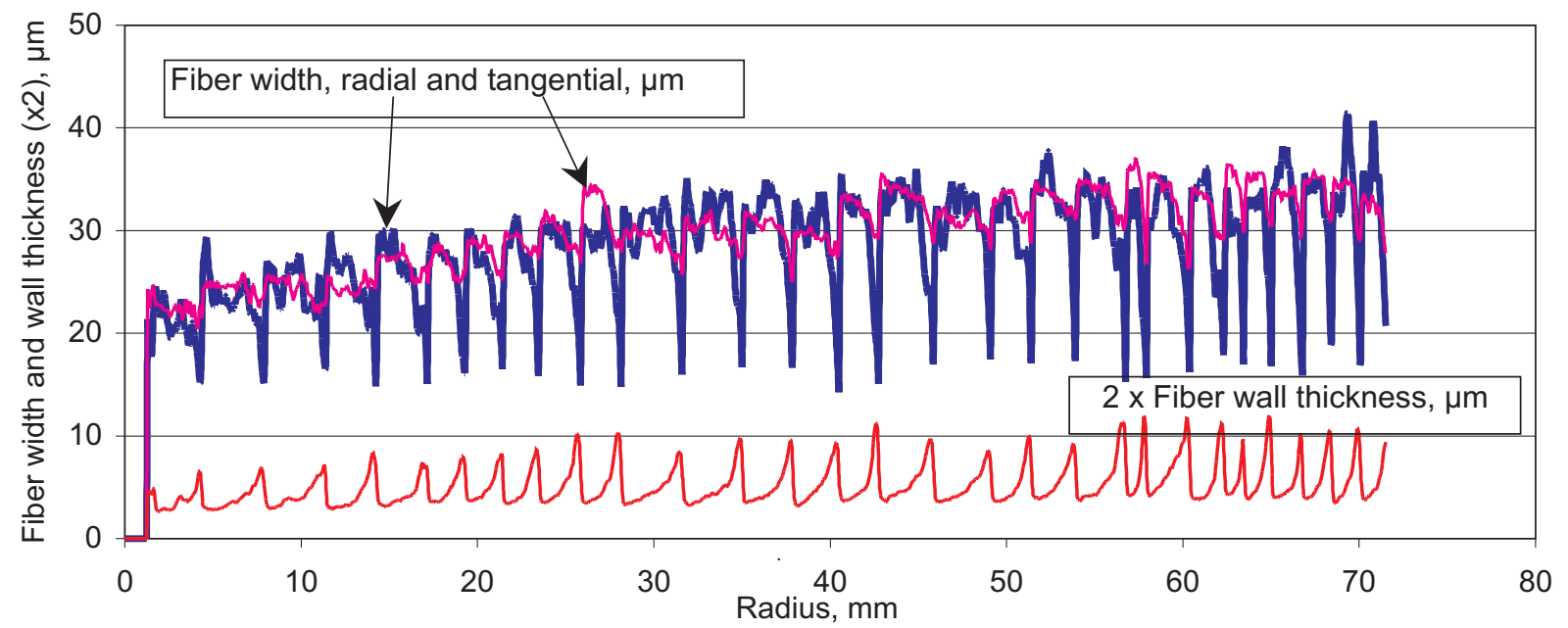

Figure 13. High resolution data on the radial variations in the cross-sectional fiber dimensions: radial and tangential fiber width and fiber wall thickness, determined by a SilviScan instrument developed at CSIRO.

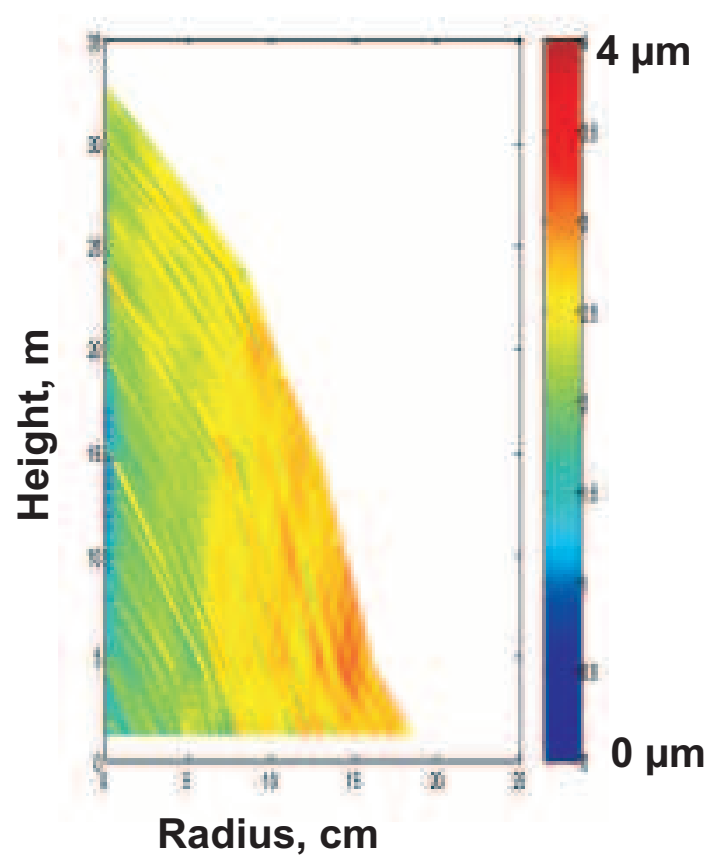

14a. Fiber wall thickness

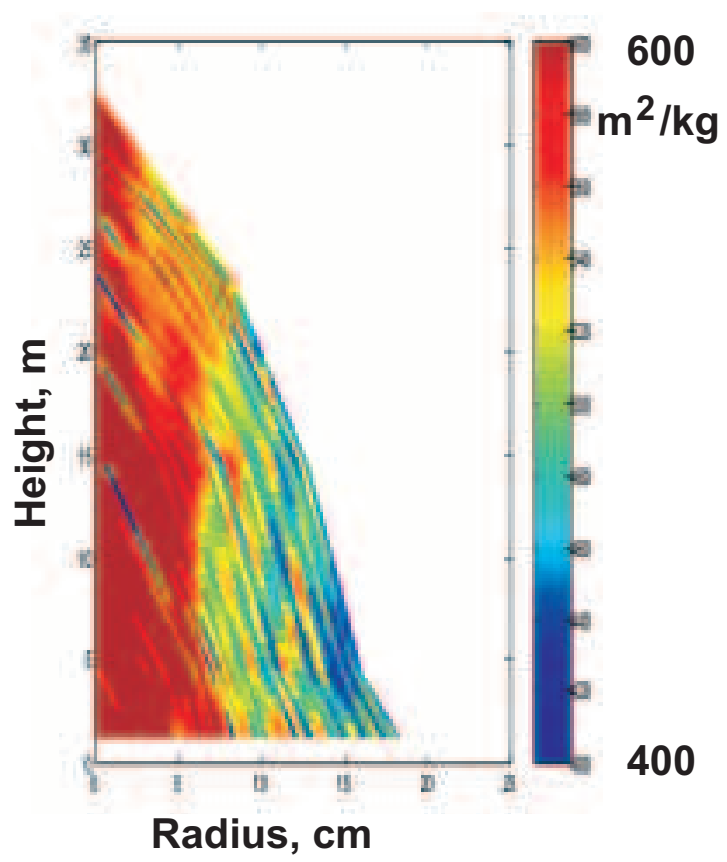

14b. Specific surface area

Figure 14. Property maps showing the within-tree variations, to the left in fiber wall thickness and to the right in specific surface area (fiber area per dry wood mass), determined by a SilviScan instrument developed by CSIRO. Same tree as in figure 8. 
the mature wood 10 and 20 meters above the ground. A clear decrease in fiber length close to the ground is also seen.

Measurements have also been performed with a SilviScan instrument at CSIRO in Melbourne, providing high resolution data on the radial variations in many wood and fiber properties from the pith (radius $0 \mathrm{~mm}$ ) to the bark, as shown in figure 13 [1]. The red graph shows the fiber wall thickness (multiplied by 2 for better visibility). The peaks indicate the latewood band of each growth ring with more slender and more thick-walled fibers. With the SilviScan, the microfibril angle (MFA) and many other parameters may also be determined. The SilviScan is a very powerful instrument for research and development. STFI will build a SilviScan instrument in cooperation with CSIRO, thereby making this unique technology more accessible for R\&D in Europe. Figure 14 shows the variability maps for the fiber wall thickness and the specific fiber area (fiber area per dry wood mass) for the same tree as above with growth ring resolution.

The methods illustrated here for the characterization of wood, fiber and vessel properties are being used by STFI within the POPWOOD and EuroFiber projects to evaluate the industrial potential of wild-type trees. Some of them will soon also be used on new plant materials. STFI has for many years been engaged in this field and has built up an arsenal of tools and knowledge, providing a platform for novel research. These methods are useful for research and development not only within the pulp and paper sector and for tree improvement, but also for research in wood technology, forestry, wood formation and many other fields.

\section{CONCLUSIONS}

When entering the phase of application of the new biotechnological tools for tree improvement, it is crucial to fully consider the industrial demands. It is also necessary to map the natural variability of the wild-type plants of today as a reference against which to assess the new materials.

Efficient methods for the characterization of wood and fiber properties are key factors for successful research and development in this field, and good measurement techniques are today available for many important properties.

Acknowledgements: Many researchers have been engaged in the activities behind the results shown. The author wishes especially to acknowledge Fredrik Ekenstedt, Thomas Grahn, Örjan Hedenberg and Lars Olsson at STFI, John Arlinger and Lars Wilhelmsson at SkogForsk, Robert Evans at CSIRO and Owe Lindgren at LTU.

\section{REFERENCES}

[1] Evans R., Downes G.M., Menz D.N.J., Stringer S.L., Rapid measurement of variations in tracheid transverse dimensions in a radiata pine tree, Appita J. 48 (1995) 134-138.

[2] Evans R., Kibblewhite R., Stringer S., Variation in microfibril angle, density and fiber orientation in twenty-nine Eucalyptus nitens trees, 53rd Appita Annual Conference, Rotorua, N. Z., 1999, pp. 487-494.

[3] Karlsson H., Fransson P.-I., STFI FiberMaster, 6th International Conference on New Available Technologies, 1999, pp. 367-374.

[4] Lindgren O., Lundqvist S.-O., Geometric transformation (warping) of CT-images - an aid for non-destructive wood density and moisture content measurements, August 21-23, 2000, IWSS 4th International Wood Scanning Seminar, Mountain Lake Resort, Virginia, USA.

[5] Olsson L., Measurement of latewood - comparison between different methods and definitions, June 19-21, 2000, Third Workshop of COST Action E10 "Wood Properties for Industrial Use": Measurement techniques, Helsinki, Finland. 
